\title{
Challenges of E-Learning System Adoption in Jordan Higher Education
}

Maha Ismail Alkhawaja, Mutia Sobihah Binti Abd Halim

To Link this Article: http://dx.doi.org/10.6007/IJARBSS/v9-i9/6317

DOI: $10.6007 /$ IJARBSS/v9-i9/6317

Received: 02 July 2019, Revised: 17 August 2019, Accepted: 02 September 2019

Published Online: 23 September 2019

In-Text Citation: (Alkhawaja \& Halim, 2019)

To Cite this Article: Alkhawaja, M. I., \& Halim, M. S. B. A. (2019). Challenges of E-Learning System Adoption in Jordan Higher Education. International Journal of Academic Research in Business and Social Sciences, 9(9), 487-494.

\section{Copyright: (C) 2019 The Author(s)}

Published by Human Resource Management Academic Research Society (www.hrmars.com)

This article is published under the Creative Commons Attribution (CC BY 4.0) license. Anyone may reproduce, distribute, translate and create derivative works of this article (for both commercial and non-commercial purposes), subject to full attribution to the original publication and authors. The full terms of this license may be seen

at: http://creativecommons.org/licences/by/4.0/legalcode

\section{Vol. 9, No. 9, 2019, Pg. 487 - 494}

Full Terms \& Conditions of access and use can be found at http://hrmars.com/index.php/pages/detail/publication-ethics 


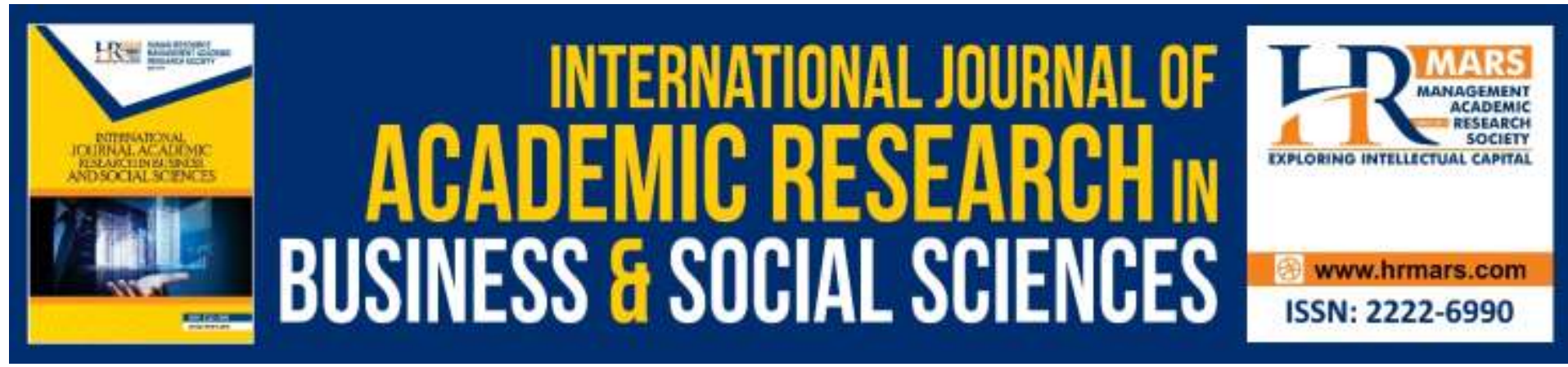

\title{
Challenges of E-Learning System Adoption in Jordan Higher Education
}

\author{
Maha Ismail Alkhawaja, Dr. Mutia Sobihah Binti Abd Halim \\ University Sultan Zainal Abidin, 21300 Kuala Terengganu, Malaysia \\ Email:memkhawajah@yahoo.com,mutiasobihah@unisza.edu.my
}

\begin{abstract}
The growth in the international community and dissemination of cultural uniformity has affected access to education. In Jordan, the curriculums need to be re-examined and get at par with current requirements for the sake of the current labor market demand for a highly disruptive technology for education such as E-learning. For the teachers and students to work in an effective educational process, Jordan has adopted E-learning projects in its higher education institutes. This study addressed a number of implications and possible future directions for blended learning in higher education. The purpose of this research is to describe and review the underlying issues and problems in e-learning adoption as it sheds light on the strengths, weaknesses, and threats that Jordan Higher Education experiences. Through a qualitative and quantitative approach, this paper will look into interviews and comments from scholars, students, and instructors in regards to the perspectives of the e-learning paradigm and tools.
\end{abstract}

Keywords: E-Learning, Blended Learning, Jordan, Globalization, Culture, Technology, Higher Education, ICT.

\section{Introduction}

Over the past decades, there has been a significant increase in Information Communication Technology (ICT) usage. The industries affected include commerce, education, and among others. ICT utilization has increased due to the new demands and the revolution in ICT. ICT plays a significant role in education as the world is evolving towards digital technology. Continuous growth has ensured that the 21st century grows and develops this technological norm (Zhou \& Teo, 2017). Higher education institutions and universities in the world have shown innovation in their technology by investing in efficient infrastructures to accommodate the increase in student numbers and improve high-quality education. Therefore, governments and university management have been prompted by Middle East education institutes to begin new ideas as they enable ICT infrastructures in education institutions (Jaber, 2016). Worldwide, there has been an improvement in communication technology. the culture in the middle east has shown some significance in the application of new technology of communication since ICT was limited (Al-shammary \& Ali, 2017). Development of ICT strategy enables economic growth because it is fundamental to utilize ICT at an initial, specifically in the education sector (Khasawneh, 2015). According to Al-Shboul and Al-Saideh 
(2017), there has been the incorporation of technological tools in many developing countries, especially in the educational system. The use of ICT in higher education instruction has seen active roles taken by students as they learn. In a contradiction, there is passive learning in traditional concept, but e-learning affects deliverance of education while enabling more access to resources. Despite the increase in adoption and use of e-learning systems (ELS) in Jordan higher education systems, there is a rise in problems attributed to the lack of quality enhancement of the inputs, processing, and outputs of e-learning systems to reach e-learning practices that are self-sustaining through an improvement in quality, which has created conflicts and challenges.

\section{Blended Education Method}

Evidently, in the traditional face to face method, teachers speak, and students listen. It is a scenario where teachers are the only source of knowledge, while the learning materials are the physical curriculum books. However, in e-learning, there is a blended teaching method in which teachers have access to use different kinds of technologies to deliver the experience. Furthermore, students have access to knowledge by using the internet to upload curriculum, notes, summaries, or reach their teachers for questions. Further, Hassan and Qudah (2018) defined blended learning as the use of modern technology into the teaching-learning process through blending goals, contents, resources, and methods into traditional knowledge to improve the learning process. Thus, face to face learning method is characterized as "traditional" by various authors, referring to the fact that this is the method with an extensive history. Moreover, blended learning represents a new or innovative intervention. For instance, the web (WWW) has been used to distribute materials because of its accessibility and usability (Rahman \& Hamid, 2017). In brief, in an ideal world, the integration of ICT into instruction was found to be useful for students' learning and achievement, and it can be fully assimilated into the curriculum.

Perennially, many studies compare the effect on students' learning outcome generated by face to face teaching method or blended learning method. According to (Bernard et al. 2014) students in blended programs achieve better results than students those unconventional classroom education programs. Although, Bahsh \& Daoud (2016) demonstrated that most university students believe that using the e-learning system in their study is a necessary part of their research as it increases the efficiency in university education, a sample of 724 students from 4 different universities was tested to come up with the findings of their perception towards ICT. According to (Al-Shboul et al., 2017), the investigated members, in regards to blended classes, were found to be $44.1 \%$ neutral and $42.0 \%$ positive. The findings led to different lines of thoughts in regards to factors improving the acceptance of students and their usage rate for e-learning systems in Jordan Universities. However, this study revealed that students face many problems and barriers using the system as they do not trust ICT services because they are unreliable and have poor quality.

Accordingly, Wong (2015) investigated the use of ELS in regards to the quality affecting the usage of students'. The findings made stated that the system is likely used if users perceived easy navigation and rerecorded with the necessary assistance whenever they experience issues. Undeniably, where quick help is accessible, users build more intention to use the system since the absence of human factor raised the need to assess the nature of e-learning system (Rahman and Hamid, 2017). Technologies and measurement implementation on the success of e-learning process could create a blended teaching method. It is possible if there 
is support on the quality of the e-learning system to enable teachers to use the system tools in their classes effectively.

\section{ICT in Jordan Higher Education: Implementation, Issues, and Challenges}

Without reservation, the among the fastest growing educational systems in the Arab district, the Jordanian higher education system has proven to be among the fastest-growing educational systems in the Arab district system is in the list. According to (Assaad, Badawy, \& Krafft, 2014), in the year 2014 to 2015, there were 290,350 thousand undergraduate and postgraduate students enrolled in higher education institutes. In this modern age, ten public universities are boosted by the Jordanian higher education in which, there are over fifty-two community colleges and twenty private universities that are equally divided in the governance of private and public institutes. Indeed, the Open University in Amman introduced a new technology known as e-learning in 2002 so that could keep up with time. It thus opened the gates to technological usage for education in students and faculty members of various Jordan universities that require pedagogical and instructional support as well as improvements (Algahtani, 2016). In the year 2003, the Jordanian Ministry of Information and Communications Technology established the nation's National Broadband Network to improve its stature as a developing country. During the creation of ICT, different strategies were used that were launched for quality improvement connection in all cities. The government of Jordan announced its project known as REACH 25 which was intended to change Jordan into an entire tech-savvy country as of the year 2015.

Subsequently, ICT programs have been established for improving the education system and ensure that it is transforming to become an e-system. Because the step is meant to enhance the quality of education, learning institutions were supposed to train staff and students to be able to use the system. In the year 1999, ICT was presented in Jordan, and this lateness in technology development created a focus on advancing the knowledge in such a phenomenon(Al-mobaideen, 2009). Years before Jordan advanced; the pursuance and implementation in the education system saw developed countries improve on quality measures for the sustenance of this technology through practical ways. Concurrently, in the year 2013, Her Majesty the Queen Rania Foundation in Edraak was the first non-profit Arabic MOOC platform which offers original Arabic courses developed by QRF. The system is supposed to broadcast short online courses offered by different experts to enrich Jordan education. For the same reason, according to INTERNET WORLD website, as of 2017 internet penetration in Jordan was $87 \%$ as opposed to Belgium, which is $94.9 \%$. While Denmark boasts of $96.9 \%$, Estonia was $97.9 \%$; Germany was $96.2 \%$ and $91 \%$ in Canada The above statistics represent reasonable communication infrastructure where a significant population is grouped as technological users. (Al-shammary \& Ali, 2017) emphasized that even though the communication technology in present became very innovative and available all over the world and the middle east is one of the leading cultures that use and adopt new technology of communication but till now the use of ICT is limited. Reasons for this limited rate of usage might rely on the availability of such technologies. In brief, the costs in Jordan still lurk behind. Accordingly, there is a sever issue to the costs of establishing ELSs in developing countries, although it is imperative to have it. It not only involves determining the system that is considered to be expensive but, system development and maintenance as well (Bringula \& Basa, 2011). To Illustrate, (Khasawneh \& Yaseen, 2017) expressed that Jordan Universities lack ELS assessment to come up with solutions for usage limitations. As opposed to developed 
countries, there have been few investigations assessing the acceptance of users in the Jordan e-learning in higher education (Alsmadi et al., 2017). Nevertheless, ELS in public and private universities was used by Jordan a few years ago; thus, the project is still young (Jaber, 2016). Therefore, it is crucial to study how Jordan Universities would improve on issues affecting ELS (Al-Shboul et al., 2017).

Also, problems and adverse factors have been specified by studies since they can impact on students and instructors in regards to their intentions towards ICT as well as their cooperation. The plans toward new education methods can be affected by the absence of communication amongst educators and student (Al-azawei, Parslow, \& Lundqvist, 2017). For instance, 14 faculty members in Al-Zaytoonah and the Applied Science University in Jordan were interviewed on their intention concerning the integration of e-learning. The findings made out that they had concerns about the availability and speed of internet in the university labs as they were concerned about the tools that they should implement during class (AlAdwan \& Smedley, 2012). Additionally, internal institutional matters from a faculty members perspective include the lack of incentives and rewards systems in encouraging faculty participation and a lack of institutional training in distant learning. According to (Al-Shboul, 2013), there is a consistent need for faculty development and institutional support in which there are primary factors that influence instructional technology in new settings of higher education.

Moreover, (Gautreau, 2011), in his study on four universities in California USA, found that all teachers surveyed were daily users of Learning Management Systems (LMS) in which onethird applied it in their teaching process. Thus, according to Al Shboul (2013), some members cannot connect to the technology in which they begged the question as to what factors "related to higher education faculty's attitudes toward the use of e-Learning in their classes?"A sample of 1314 faculty members of The University of Jordan was sent survey questionnaires and the findings made found out that, i.e. $26.8 \%$ used tools like Black Boards in e-learning. Forty-nine faculty members, i.e. $18.3 \%$, used delivery tools in JU's Faculty Member Website and, 30 faculty members, i.e. 11.2\%, used Moodle for delivery of their classroom instructions. Additionally, 117 i.e. $43.7 \%$ used any e-Learning tools. The reason behind this is that institutors were the ones who determined the usage of available learning system hence reduces the merits obtained from utilizing the system. Besides, further studies are recommended to be conducted to find factors that affect faculties and illuminate ELS use. However, since 2003, the UJ introduced an integrated LMS system that was fused with the information system as it took e-learning and ICT development. Further, in the year 2005 and 2012, respectively, Blackboard and Moodle were used as a central learning management system LMS. For instance, module descriptions and assignments can be uploaded by the course instructor while students can access them by downloading the tasks which indicate that the use is still in the beginning stage (Almarabeh, 2014).

To demonstrate, Jordanian higher education is affected by different factors such as conservative cultures, lack of legal frameworks, censorship systems, untrained staff, traditional pedagogies, dearth financial resources, and weak infrastructure in the adoption and quality improvement of e-learning(Osman, 2018). Moreover, educational systems in Jordan are overstressed by the flow of Arab refugees from its neighbors who suffer political stalemates hence create challenges for the adoption of new techniques and strategies to provide quality education for all (Jalbout \& Farah, 2016). 


\section{Conclusion}

Due to the lack of adoption in E-learning, it has proven to have its disadvantages, which are attributed to the issues and challenges that have led to slow growth in its implementation. By focusing on quality issues, the benefits are supposed to outweigh the obstacles as the Jordan higher education system considers to invest more on the same in addressing the key challenges. Many problems accompany the adoption of E-learning in Jordan. Such issues include technical issues that are as a result of low bandwidth or the weak internet connection. There is the problem of adaptability struggles that have seen many stakeholders in Jordan having a hard time moving from traditional classrooms to getting adapted to Course Management Systems (CMS). Computer illiteracy is also a significant problem in Jordan despite many students being tech-savvy since they may lack skills to operate basic operations such as handling files and the programs that are associated with them. Time Management also plays a significant role as students experience a problematic task because online tasks require a lot of time and intensive work. Many learners in Jordan also lack self-motivation since many learners in Jordan fall behind and nurture the idea of giving up, as difficulties in handling a technological medium also seem impossible. Furthermore, there is the problem that many people in Jordan may believe that learning offers no support as this paper fund out; hence, there is less enrollment in a learning course. In brief, learners cannot see the real world implications of the eLearning course.

Besides, this paper finds that E-Learning is meant to ensure that it accommodates everyone's needs, for instance, there is access to updated content, lessons are quickly delivered, there are reduced costs, and there is less impact on the environment. Furthermore, it promotes scalability in terms of the creation and communication of new training, policies, concepts, and ideas. From the in-depth qualitative findings, it would be recommended that significant improvements to the e-learning system in Jordan universities are required to reach users expectations. The e-learning systems should accommodate the innovative design trends which should inevitably attract students to use and interact with the systems in Jordan. As a recommendation, E-learning systems should engage its stakeholders through keeping it visually simple, choosing the right color of fonts, making navigation easy, using microlearning, socializing the interface, include self-assessment and gamify it to motivate and reward the sense of completion. Therefore, the higher education institutions in Jordan should focus on improving the higher retention of learning material, which is based on the self-interest of students. They should allow flexibility, self-paced learning, and enhanced technological support. For all these to work, Jordan education system should ensure that there are an excellent student collaboration and teacher interaction. It is without a doubt that Jordan wants to build up the economy in knowledge and expand institutional barriers through elearning to achieve a healthy market. In the future, it would be prudent to aim and understand the drivers and barriers of e-learning in Jordan from a multistakeholder perspective.

\section{Acknowledgment}

I would like to express my sincere gratitude to both, my supervisor Dr. Mutia Sobihah Binti Abd Halim and my guardian Eng. Nasser Alkhawaja for their continuous support of my study and research, for their guidance, patience, motivation, enthusiasm and immense knowledge. 


\section{References}

Al-Adwan, A., \& Smedley, J. (2012). Implementing e-learning in the Jordanian Higher Education System: Factors affecting impact. International Journal of Education and Development Using Information and Communication Technology (IJEDICT), 8(1), 121135. Retrieved from https://pdfs.semanticscholar.org/67a7/cdca7f0b1abc2be96f7a2d13a2391a86043c.pdf

Al-azawei, A., Parslow, P., \& Lundqvist, K. (2017). Investigating the effect of learning styles in a blended e-learning system : An extension of the technology acceptance model ( TAM ), 33(November), 1-23. https://doi.org/10.14742/ajet.2758

Al-gahtani, S. S. (2016). Empirical investigation of e-learning acceptance and assimilation : A structural equation model. APPLIED COMPUTING AND INFORMATICS. https://doi.org/10.1016/j.aci.2014.09.001

Al-mobaideen, H. O., \& Uk, L. M. U.-. (2009). Ict diffusion in jordanian universities, 2009(2004), $1-21$.

Al-shammary, S., \& Ali, A. A. (2017). ICT Hindering Factors Applied in Jordan Construction Projects. Civil Engineering and Architecture 5(3):, 5(3), 83-88. https://doi.org/10.13189/cea.2017.050302

Al-Shboul, M. (2013). The level of E-learning integration at the University of Jordan: Challenges and opportunities. International Education Studies, 6(4), 93-113. https://doi.org/10.5539/ies.v6n4p93

Al-Shboul, M., Al-Saideh, M., \& Al-Labadi, N. (2017). Learners' perspectives of using ICT in higher education institutions in Jordan, (November).

Almarabeh, T. (2014). Students ' Perceptions of E-Learning at the University of Jordan, 9(3), 31-35.

Alsmadi, D., Jianping, C., Prybutok, V., \& Gadgil, G. (2017). E-Learning in Jordanian Higher Education: Cultural Perspectives and Institutional Readiness. Journal of Information \& Knowledge Management, 16(4), 1750035. https://doi.org/10.1142/S0219649217500356

Assaad, R., Badawy, E., \& Krafft, C. (2014). No Title. Retrieved from https://erf.org.eg/wpcontent/uploads/2014/07/828.pdf

Bahsh, R. El, \& Daoud, M. I. (2016). Evaluating the Use of Moodle to Achieve Effective and Interactive Learning : A Case Study at the German Jordanian University, 16-20.

Bernard, R. M., Borokhovski, E., Schmid, R. F., Tamim, R. M., \& Abrami, P. C. (2014). A metaanalysis of blended learning and technology use in higher education: From the general to the applied. Journal of Computing in Higher Education, 26(1), 87-122. https://doi.org/10.1007/s12528-013-9077-3

Bringula, R. P., \& Basa, R. S. (2011). Factors affecting faculty web portal usability. Educational Technology and Society, 14(4), 253-265.

Gautreau, C. (2011). Motivational Factors Affecting the Integration of a Learning Management System by Faculty. The Journal of Educators Online, 8(1), 1-25. https://doi.org/10.9743/jeo.2011.1.2

Jaber, O. A. (2016). An Examination of Variables Influencing the Acceptance and Usage of ELearning Systems in Jordanian Higher Education Institutions, 244.

Jalbout, M., \& Farah, S. (2016). Will the Technology Disruption Widen or Close the Skills Gap in the Middle East and North Africa?, (March).

Khasawneh, M. (2015). Factors Influence e-Learning Utilization in Jordanian Universities - 
Academic Staff Perspectives. Procedia - Social and Behavioral Sciences, 210, 170-180. https://doi.org/10.1016/j.sbspro.2015.11.356

Khasawneh, M., \& Yaseen, A. B. (2017). Critical Success Factors for E-Learning Satisfaction, Jordanian Universities' Experience. Journal of Business \& Management Journal of Business \& Management (COES\&RJ-JBM), 55(11), 2306-7179. Retrieved from http://centreofexcellence.net/J/JBM/JBM Mainpage.htm

Osman, G. (2018). Formal e-Learning in Arab Countries: Challenges and Opportunities. Learning, Design, and Technology, 1-26. https://doi.org/10.1007/978-3-319-177274_34-1

Rahman, N. A. A., \& Hamid, N. H. A. (2017). E-learning service quality. International Conference on Research and Innovation in Information Systems, ICRIIS. https://doi.org/10.1109/ICRIIS.2017.8002449

Wong, W. (2015). The Effects of E-Learning System Service Quality and Users ' Acceptance on Organizational Learning, 6(2).

Zhou, M., \& Teo, T. (2017). Qualitative evidence from a developing country. International Journal of Educational Technology, 4(1), 26-33. Retrieved from http://educationaltechnology.net/ijet/ 